\title{
Damage Assessment of Heat Resistant Steels through Electron BackScatter Diffraction Strain Analysis under Creep and Creep-Fatigue Conditions*
}

\author{
Kazunari FUJIYAMA**, Hirohisa KIMACHI**, Toshiki TSUBOI***, \\ Hiroyuki HAGIWARA***, Shotaro OGINO*** and Yoshiki MIZUTANI*** \\ ${ }^{* *}$ Department of Mechanical Engineering, Meijo University \\ 1-501 Shiogamaguchi, Tempaku-ku, Nagoya, Japan \\ E-mail: fujiyama@meijo-u.ac.jp \\ ${ }^{* * *}$ Graduate School of Mechanical Engineering, Meijo University \\ 1-501 Shiogamaguchi, Tempaku-ku, Nagoya, Japan
}

\begin{abstract}
EBSD(Electron BackScatter Diffraction) analyses were conducted for studying the quantitative microstructural metrics of creep and creep-fatigue damage for austenitic SUS304HTB boiler tube steel and ferritic Mod.9Cr piping steel. KAM(Kernel Average Misorientation) maps and GOS(Grain Orientation Spread) maps were obtained for these samples and the area averaged values $K A M_{\text {ave }}$ and $G O S_{\text {ave }}$ were obtained. While the increasing trends of these misorientation metrics were observed for SUS304HTB steel, the decreasing trends were observed for damaged Mod.9Cr steel with extensive recovery of subgrain structure. To establish more universal parameter representing the accumulation of damage to compensate these opposite trends, the EBSD strain parameters were introduced for converting the misorientation changes into the quantities representing accumulated permanent strains during creep and creep-fatigue damage process. As $K A M$ values were dependent on the pixel size (inversely proportional to the observation magnification) and the permanent strain could be expressed as the shear strain which was the product of dislocation density, Burgers vector and dislocation movement distance, two KAM strain parameters $M_{\varepsilon K A M n e t}$ and $M_{\varepsilon \delta K A M a v e}$ were introduced as the sum of product of the noise subtracted $K A M_{\text {net }}$ and the absolute change from initial value $\delta K A M_{\text {ave }}$ with dislocation movement distance divided by pixel size. $M_{\varepsilon \delta K A M a v e}$ parameter showed better relationship both with creep strain in creep tests and accumulated creep strain range in creep-fatigue tests. This parameter can be used as the strain-based damage evaluation and detector of final failure.
\end{abstract}

Key words: EBSD, Creep, Creep-Fatigue, Damage, Austenitic Stainless Steel, High Chromium Steel, Strain

\section{Introduction}

Austenitic stainless steels and high chromium tempered martinsitic heat resistant steels are widely used as key component materials to endure the severe condition of steam pressure and temperature in modern fossil power plants[1]. However those material degradation and damage accumulation processes might not be fully understood 
quantitatively according to the complex nature of microstructural change. Although the enormous efforts have been done to reveal the micromechanism of degradation and damage during creep process using Transmission Electron Microscope (TEM) or other sophisticated equipment, the quantification of the phenomena is still a challenging task[2].

Recently, Electron BackScatter Diffraction pattern (EBSD) method has been successfully applied to investigate the crystallographic characteristics of dislocation substructure and grain/subgrain morphologies[3]. Among the EBSD parameters, quantities related to misorientation could represent the change of local crystal rotation but it could not have been directly correlated with the plastic strains or creep strains.

Meanwhile, several extensive studies have been conducted on the relationships between inelastic strains and EBSD parameters, such as on the relationship between the distribution of misorientation and crystal slip [3], on the crystal deformation parameter[4] and on the effect of grain size and EBSD pixel step size $[5,6]$.

The permanent creep or plastic strain can be interpreted in principle as the resultant quantity from the combination of dislocation density and dislocation motion. Misorientation measured by EBSD is apparently correlated with the dislocation distribution but it does not represent the mobile dislocation density itself. Moreover, EBSD parameters are inevitably affected by the observation magnification i.e. the pixel step size[7].

To establish the evaluation method of accumulated permanent strain during creep and creep-fatigue damage process, special attention was paid on the change of EBSD parameters KAM(Kernel Average Misorientation) and GOS(Grain Orientation Spread) based on experimental results. KAM based strain parameters were introduced for obtaining good correlations with the macroscopic strains both for creep and creep-fatigue damage process.

\section{Experimental Procedure}

\subsection{Materials}

Tested materials used are the plate of simulated SUS304HTB steel as austenitic stainless steel for boiler tube material and the plate of simulated Mod.9Cr steel as- tempered martensitic steel for piping material of high temperature component. Table 1 and Table 2 show the chemical composition and the tensile properties at ambient temperature.

Table 1 Chemical composition (mass \%).

\begin{tabular}{|c|c|c|c|c|c|c|c|c|c|c|c|}
\hline Material & $\mathrm{C}$ & $\mathrm{Si}$ & $\mathrm{Mn}$ & $\mathrm{P}$ & $\mathrm{S}$ & $\mathrm{Cr}$ & $\mathrm{Mo}$ & $\mathrm{Ni}$ & $\mathrm{V}$ & $\mathrm{Cu}$ & $\mathrm{N}$ \\
\hline SUS304HTB & 0.06 & 0.53 & 1.45 & 0.025 & 0.012 & 18.38 & 0.22 & 10.04 & $<0.01$ & 0.12 & 0.029 \\
\hline Material & $\mathrm{C}$ & $\mathrm{Si}$ & $\mathrm{Mn}$ & $\mathrm{P}$ & $\mathrm{S}$ & $\mathrm{Cr}$ & $\mathrm{Mo}$ & $\mathrm{Ni}$ & $\mathrm{V}$ & $\mathrm{Nb}$ & $\mathrm{N}$ \\
\hline Mod.9Cr & 0.084 & 0.385 & 0.0375 & 0.10 & 0.001 & 8.34 & 0.89 & 0.28 & 0.018 & 0.074 & 0.048 \\
\hline
\end{tabular}

Table 2 Tensile properties at ambient temperature.

\begin{tabular}{|c|c|c|c|}
\hline Material & $\begin{array}{c}0.2 \% \text { proof stress } \\
(\mathrm{MPa})\end{array}$ & $\begin{array}{c}\text { Tensile strength } \\
(\mathrm{MPa})\end{array}$ & $\begin{array}{c}\text { Elongation } \\
(\%)\end{array}$ \\
\hline SUS304HTB & 253 & 594 & 61 \\
\hline Mod.9Cr steel & 526 & 690 & 29 \\
\hline
\end{tabular}

\subsection{Creep Test}

Creep tests were conducted on round bar specimens using single lever type creep testing machines. Figure 1 shows the specimen geometry with $6 \mathrm{~mm}$ diameter and $30 \mathrm{~mm}$ gage 
length. Tables 4 and 5 show the creep rupture and creep interruption test conditions with corresponding nominal creep strain for interruption test specimen and nominal creep rupture strain for ruptured specimen.

The center portions of specimens shown as hatched area were longitudinally sectioned for observation sampling. For EBSD observation, mid-sections of the specimens were polished by sand paper (No.180-No.2000) and by buff with Alumina slurry (particle size $3 \mu \mathrm{m}$ to $0.1 \mu \mathrm{m})$. Sample surface preparation was conducted up to the final polishing with colloidal silica.

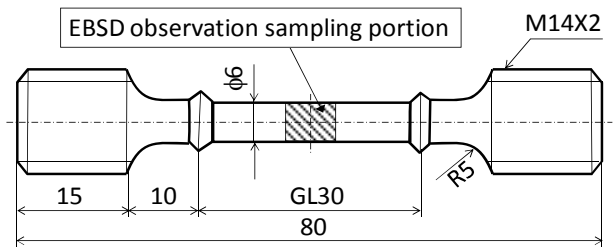

Fig.1. Creep test specimen and sampling portion.

Table 4 Creep rupture and interruption test conditions for SUS304HTB.

\begin{tabular}{|c|c|c|c|c|}
\hline $\begin{array}{c}\text { Test temperature } \\
\left({ }^{\circ} \mathrm{C}\right)\end{array}$ & $\begin{array}{c}\text { Stress } \\
(\mathrm{MPa})\end{array}$ & $\begin{array}{c}\text { Imposed time } \\
(\mathrm{h})\end{array}$ & $\begin{array}{c}\text { Time fraction } \\
t / t_{r}\end{array}$ & $\begin{array}{c}\text { Creep strain } \\
\varepsilon_{c}\end{array}$ \\
\hline \multirow{4}{*}{650} & & 75.4 & 0.1 & 0.021 \\
\cline { 3 - 5 } & \multirow{3}{*}{130} & 166 & 0.22 & 0.086 \\
\cline { 3 - 5 } & & 377.3 & 0.5 & 0.096 \\
\cline { 3 - 5 } & & 616.3 & 0.82 & 0.159 \\
\cline { 3 - 5 } & & 754.6 & 1 & 0.445 \\
\hline
\end{tabular}

Table 5 Creep rupture and interruption test conditions for Mod.9Cr steel.

\begin{tabular}{|c|c|c|c|c|}
\hline $\begin{array}{c}\text { Test temperature } \\
\left({ }^{\circ} \mathrm{C}\right)\end{array}$ & $\begin{array}{l}\text { Stress } \\
(\mathrm{MPa}) \\
\end{array}$ & $\begin{array}{c}\text { Imposed time } \\
\text { (h) }\end{array}$ & $\begin{array}{c}\text { Time fraction } \\
t / t_{r}\end{array}$ & $\begin{array}{c}\text { Creep strain } \\
\varepsilon_{c} \\
\end{array}$ \\
\hline \multirow{5}{*}{600} & \multirow{5}{*}{130} & 471 & 0.1 & 0.008 \\
\hline & & 943 & 0.2 & 0.009 \\
\hline & & 2347 & 0.5 & 0.021 \\
\hline & & 3762 & 0.8 & 0.036 \\
\hline & & 4704 & 1 & 0.112 \\
\hline \multirow{5}{*}{650} & \multirow{5}{*}{100} & 53.7 & 0.1 & 0.007 \\
\hline & & 108.1 & 0.2 & 0.008 \\
\hline & & 267 & 0.5 & 0.015 \\
\hline & & 427.1 & 0.8 & 0.045 \\
\hline & & 533.8 & 1 & 0.169 \\
\hline
\end{tabular}

\subsection{Creep-fatigue Test}

Creep-fatigue tests were conducted on round bar specimens by strain-controlled electric-hydraulic servo testing machine with induction heater. Figure 2 shows the specimen geometry with $8 \mathrm{~mm}$ diameter and $20 \mathrm{~mm}$ gage length. Figure 3 shows the schematic of the stress-strain hysteresis loop for tensile strain hold wave shape where inelastic strain range $\Delta \varepsilon_{i e}$ and creep strain range $\Delta \varepsilon_{c}$ are defined. Tables 6 and 7 show the creep-fatigue failure and interruption test conditions with representative strain ranges measured at $N_{f} / 2$ cycles for fractured specimens. The failure cycles $N_{f}$ were determined as the cycles at $25 \%$ drop of peak stress after deviation point from the steady state of peak stress changes with cycles. 
The tension-compression strain rate was set as $0.01 \% / \mathrm{s}$.

The center portion of specimens shown as hatched area was longitudinally sectioned and polished for observation after the creep-fatigue tests. For EBSD observation, mid-sections of the specimens were polished in the similar manner for creep test specimen.

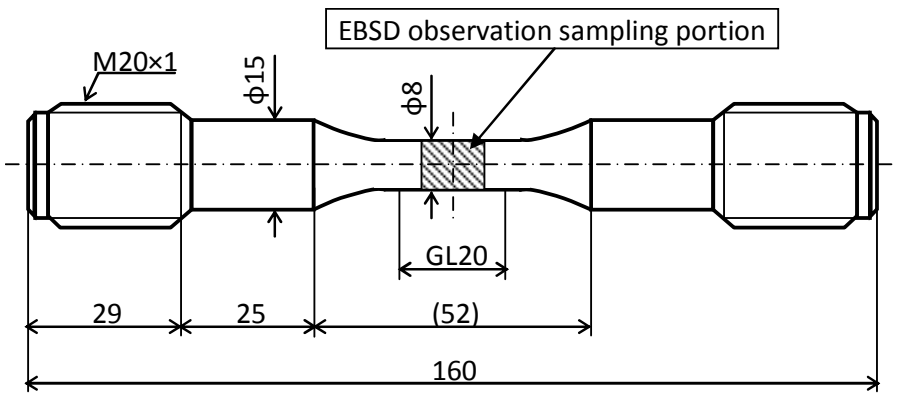

Fig.2. Creep-fatigue test specimen and sampling portion.

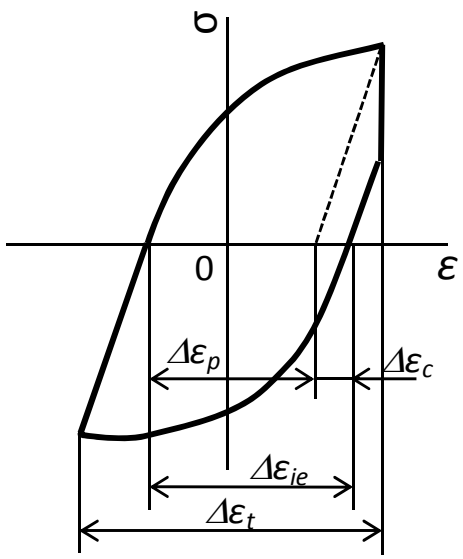

Fig.3 Schematic of the stress-strain hysteresis loop for tensile strain hold waveshape.

Table 6 Creep-fatigue failure and interruption test conditions for SUS304HTB

\begin{tabular}{|c|c|c|c|c|c|c|}
\hline $\begin{array}{c}\text { Test } \\
\text { temperature } \\
\left({ }^{\circ} \mathrm{C}\right)\end{array}$ & $\begin{array}{c}\text { Total strain } \\
\text { range } \\
\Delta \varepsilon_{t}\end{array}$ & $\begin{array}{c}\text { Inelastic strain } \\
\text { range } \\
\Delta \varepsilon_{i e}\end{array}$ & $\begin{array}{c}\text { Creep strain } \\
\text { range } \\
\Delta \varepsilon_{c}\end{array}$ & $\begin{array}{c}\text { Hold time } \\
(\text { min })\end{array}$ & $\begin{array}{c}\text { Number } \\
\text { of cycles } \\
N\end{array}$ & $\begin{array}{c}\text { Cycle } \\
\text { fraction } \\
N / N_{f}\end{array}$ \\
\hline 650 & 0.01 & 0.0075 & 0.00047 & 10 & 128 & 0.17 \\
\cline { 5 - 7 } & & & & & 740 & 0.5 \\
\hline
\end{tabular}

Table 7 Creep-fatigue failure and interruption test conditions for Mod.9Cr steel

\begin{tabular}{|c|c|c|c|c|c|c|}
\hline $\begin{array}{c}\text { Test } \\
\text { temperature } \\
\left({ }^{\circ} \mathrm{C}\right)\end{array}$ & $\begin{array}{c}\text { Total strain } \\
\text { range } \\
\Delta \varepsilon_{t} \\
\end{array}$ & $\begin{array}{c}\text { Tensile strain } \\
\text { rate } \\
\Delta \varepsilon_{i e} \\
\end{array}$ & $\begin{array}{c}\text { Compressive } \\
\text { strain rate } \\
\Delta \varepsilon_{c} \\
\end{array}$ & $\begin{array}{l}\text { Hold time } \\
\qquad(\mathrm{min})\end{array}$ & $\begin{array}{c}\text { Number } \\
\text { of cycles } \\
N \\
\end{array}$ & $\begin{array}{c}\text { Cycle } \\
\text { fraction } \\
N / N_{f}\end{array}$ \\
\hline \multirow{7}{*}{650} & \multirow{7}{*}{0.01} & \multirow{5}{*}{0.0085} & \multirow{5}{*}{0.00068} & \multirow{5}{*}{10} & 106 & 0.1 \\
\hline & & & & & 265 & 0.25 \\
\hline & & & & & 529 & 0.5 \\
\hline & & & & & 794 & 0.75 \\
\hline & & & & & 1058 & 1 \\
\hline & & \multirow{2}{*}{0.0088} & \multirow{2}{*}{0.00082} & \multirow{2}{*}{30} & 230 & 0.5 \\
\hline & & & & & 460 & 1 \\
\hline
\end{tabular}




\subsection{EBSD Observation}

EBSD observation was conducted using the EBSD system (Tex SEM Laboratory: OIM 4.6) instrumented in Scanning Electron Microscope (SEM), JSM7000FS by JEOL. In this study, KAM maps and GOS maps were made from the observation data.

Figure 4 shows the procedure for calculating KAM and GOS values from subject maps. The calculated variables are hereafter denoted in italics like $K A M$ and GOS. KAM estimated from the adjacent neighboring pixel angles is strongly dependent on step size $d_{s}$ as defined in Fig.4, which is inversely proportional to the magnification of observation but $G O S$ is supposed more independent on $d_{s}$ because of the averaging effect of step sizes using overall intragranular spacing. The averaged values over observed areas are calculated as the averaged $K A M$ and $G O S$ values for all pixels in a map and denoted as $K A M_{\text {ave }}$ and $G O S_{\text {ave }}$.

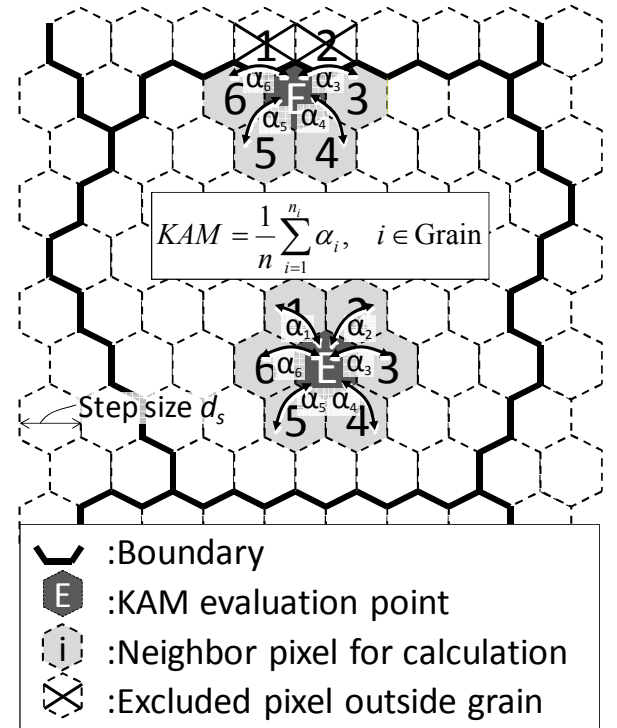

(a)KAM

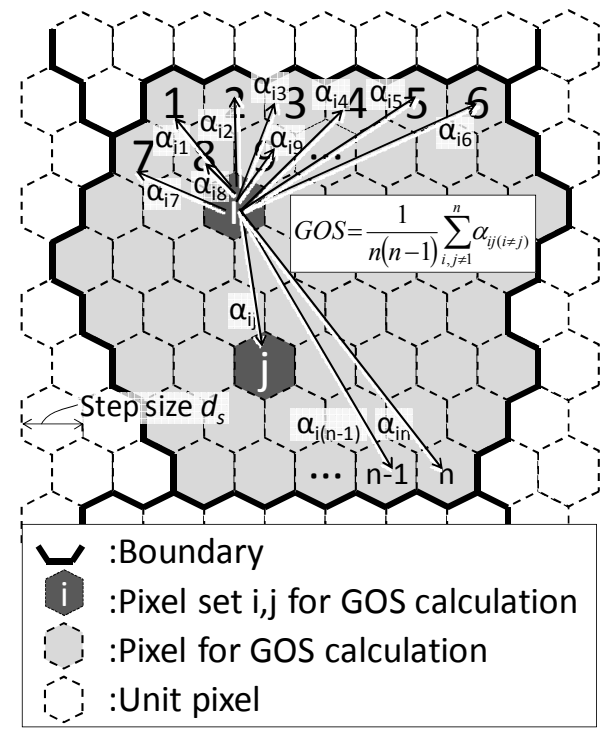

(b)GOS

Fig.4. Definition of EBSD parameters.

The magnifications for SEM/EBSD observation were $\times 250\left(d_{s}=2 \mu \mathrm{m}\right), \times 500\left(d_{s}=1 \mu \mathrm{m}\right)$, $\times 1000\left(d_{s}=0.5 \mu \mathrm{m}\right)$ for SUS304HTB and $\times 2000\left(d_{s}=0.25 \mu \mathrm{m}\right), \quad \times 3000\left(d_{s}=0.167 \mu \mathrm{m}\right)$, $\times 5000\left(d_{s}=0.1 \mu \mathrm{m}\right)$ for Mod.9Cr steel keeping the same position for changing the magnification. The higher magnifications for Mod.9Cr steel than SUS304HTB is due to smaller size of boundaries corresponding to blocks inside the prior austenite grains.

\section{Results}

Figures 5 shows the KAM maps for as-received, creep damaged and creep-fatigue damaged SUS304HTB samples. The area of misorientation angle over $1^{\circ}$ increased with the increase of time fraction and cycle fraction showing the change of dislocation substructure. The solid lines show the boundaries of the misorientation over $15^{\circ}$ which correspond to the austenite grain boundaries or twin boundaries. The change of $K A M$ distribution with damage accumulation is more extensive in creep-fatigue tests than in creep tests, though the observation magnification is smaller in creep-fatigue tests than creep tests. 


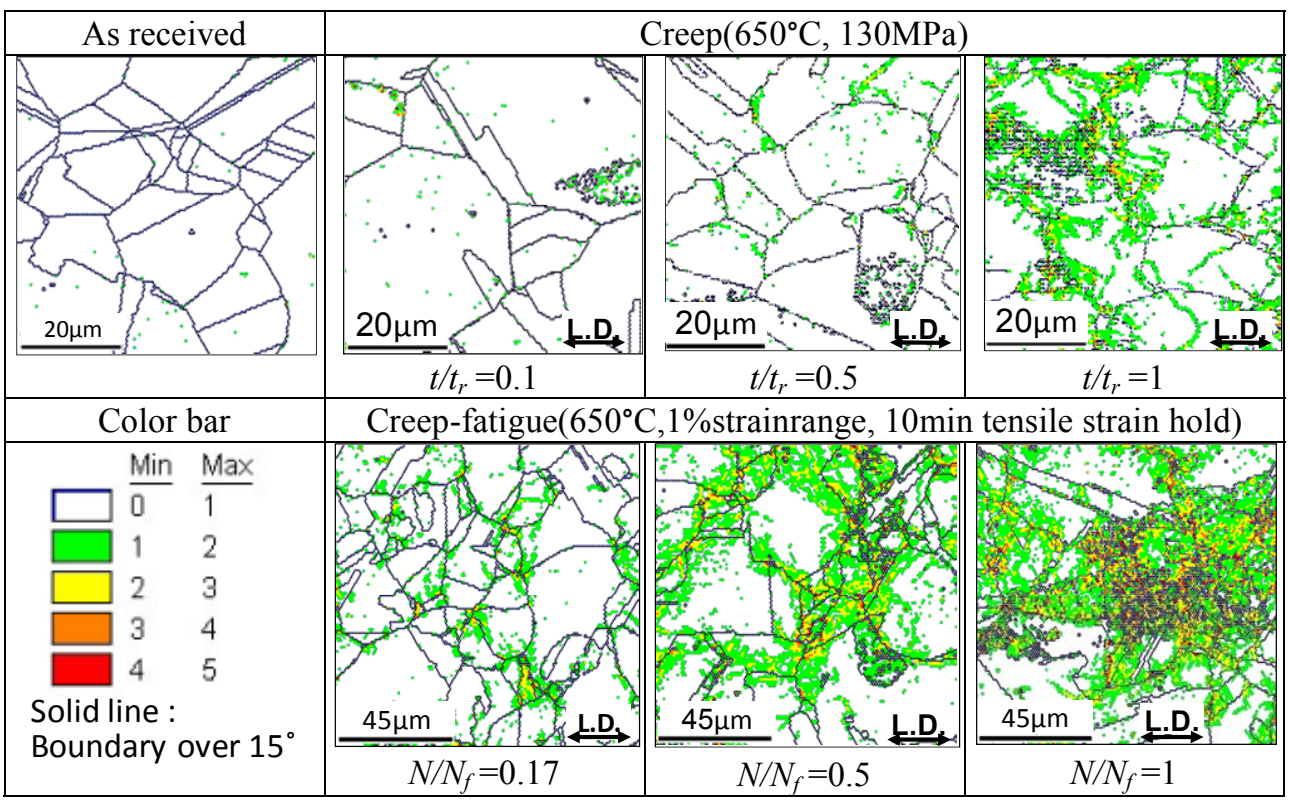

Fig.5. KAM maps for creep and creep-fatigue damaged SUS304HTB.

Figures 6 shows the KAM maps for as-received, creep damaged and creep-fatigue damaged Mod.9Cr steel samples. While the gradual decrease in the area of KAM over $1^{\circ}$ (mainly below $2^{\circ}$ ) and block size coarsening were observed during the accumulation of creep damage, extensive decrease in the area of KAM over $1^{\circ}$ and block size coarsening were observed even in the very early stage of creep-fatigue damage accumulation.

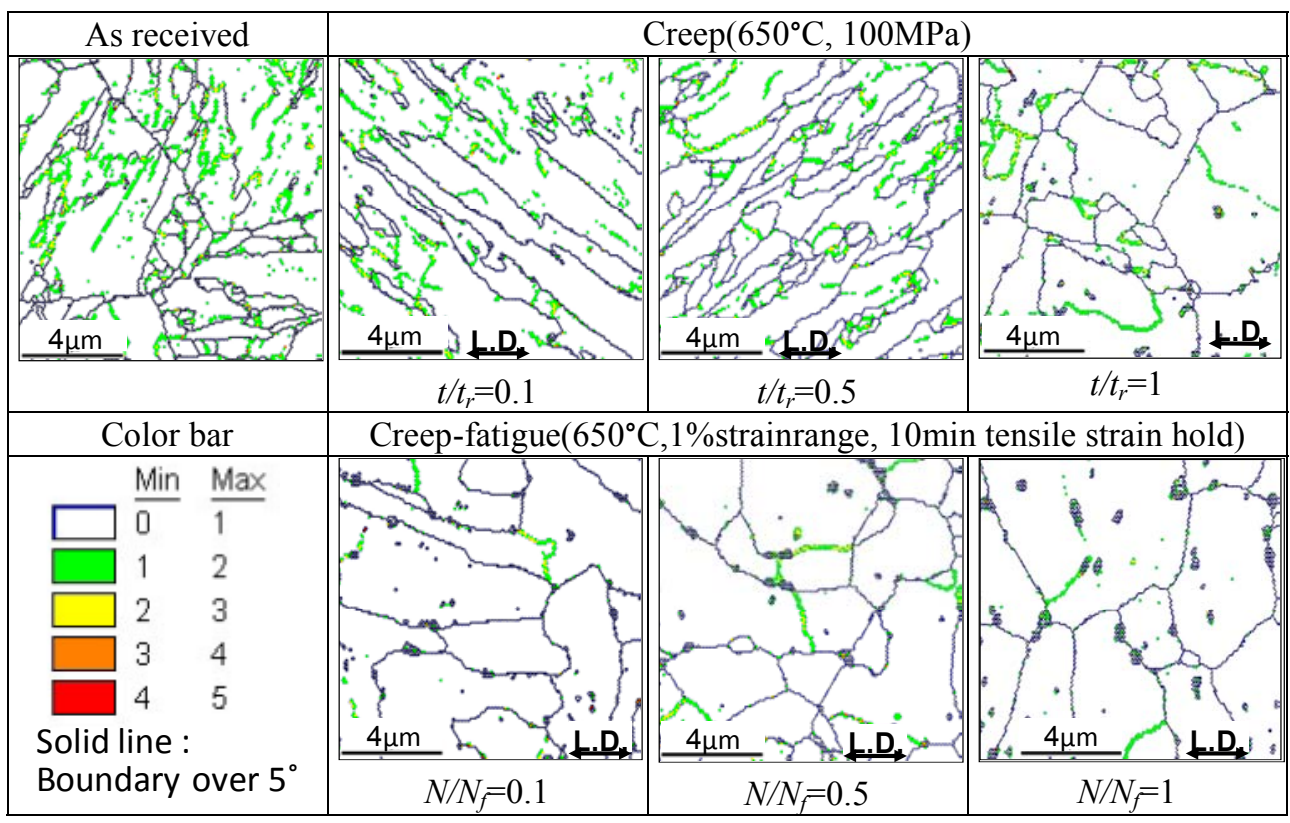

Fig.6 KAM maps for creep and creep-fatigue damaged Mod.9Cr steel.

Figure 7 shows the relationship between $K A M_{\text {ave }}$ and time or cycle fraction for creep and creep-fatigue damaged SUS304HTB. The increasing trend in $K A M_{\text {ave }}$ was observed for SUS304HTB. The step size effect is apparent.

Figure 8 shows the relationship between $G O S_{\text {ave }}$ and time or cycle fraction for creep and creep-fatigue damaged SUS304HTB. The effect of step size is not so apparent as compared 
with the case of $K A M_{\text {ave }}$. The increasing trend in $G O S_{\text {ave }}$ during creep damage accumulation was observed while monotonic trend was not observed especially over 0.5 in $N / N_{f}$ during creep-fatigue damage process.

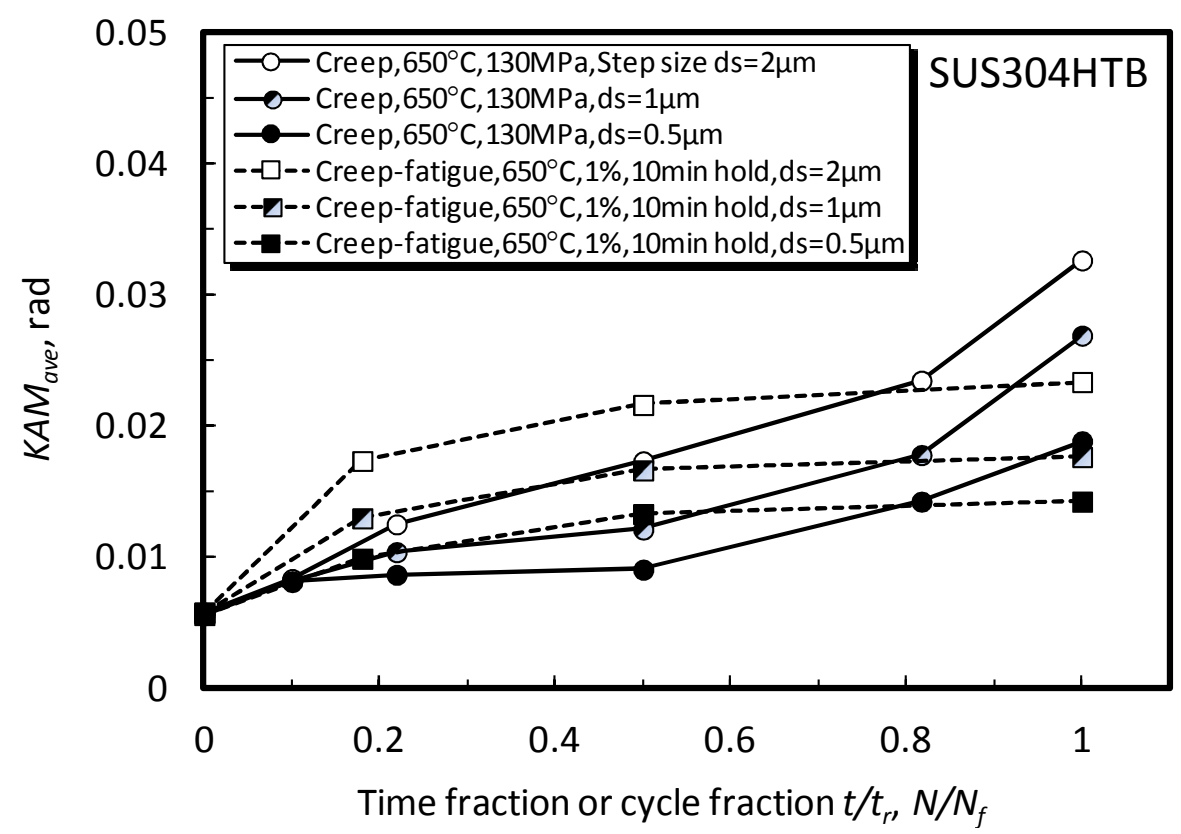

Fig.7. Relationships between $K A M_{\text {ave }}$ and time or cycle fraction for creep and creep-fatigue tests of SUS304HTB.

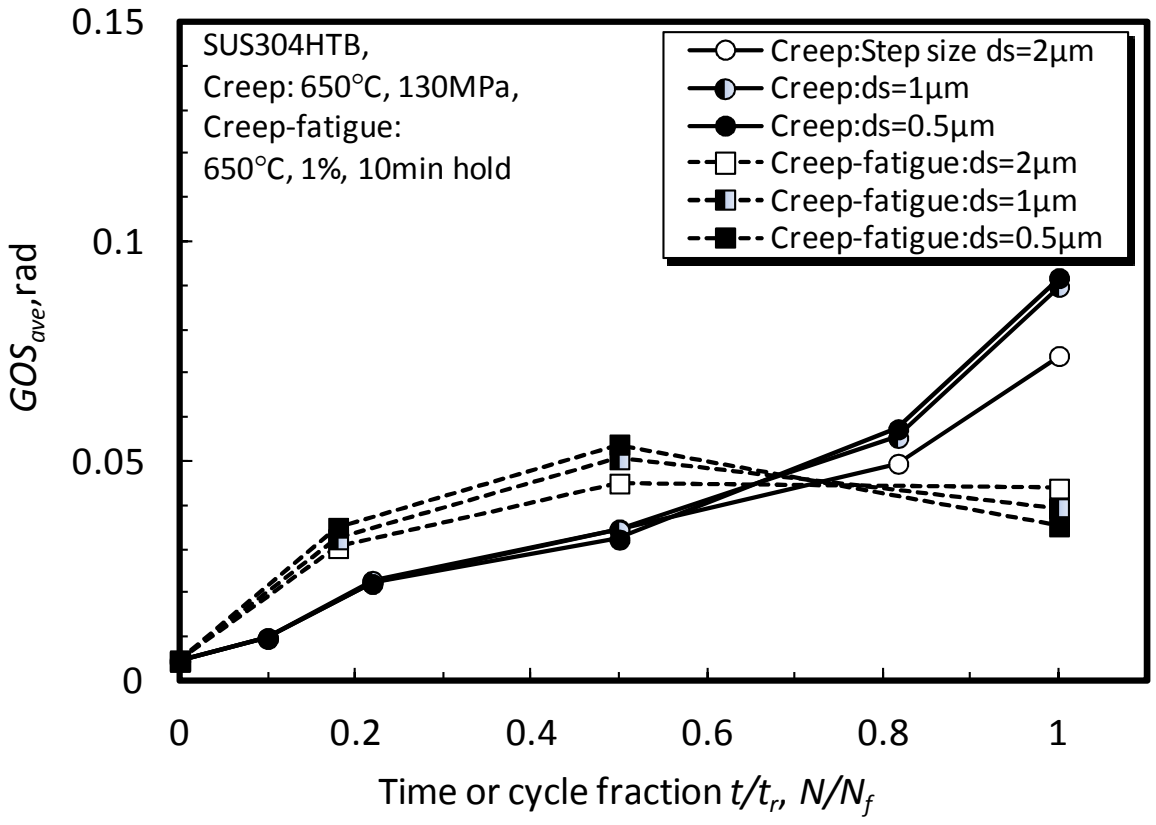

Fig.8. Relationships between $G O S_{a v e}$ and time or cycle fraction for creep and creep-fatigue tests of SUS304HTB.

Figure 9 shows the relationship between $K A M_{\text {ave }}$ and time or cycle fraction for creep and creep-fatigue damaged Mod.9Cr steel. The initial decreasing trend in $K A M_{\text {ave }}$ was observed showing some differences in the overall trend between creep and creep-fatigue.

Figure 10 shows the relationship between $G O S_{\text {ave }}$ and time or cycle fraction for creep and creep-fatigue damaged $\mathrm{Mod} .9 \mathrm{Cr}$ steel. The initial decrease trend was observed in 
$G O S_{\text {ave }}$ but the effect of step size is not so apparent in creep compared with $K A M_{\text {ave }}$ and the difference between creep and creep-fatigue was also observed.

\begin{tabular}{|c|c|}
\hline \multirow{2}{*}{\multicolumn{2}{|c|}{ Z-Creen $600^{\circ} \mathrm{C} 130 \mathrm{MPa}$ Sten size ds $=025 \mu \mathrm{m}$}} \\
\hline & $\rightarrow-C r e e p, 600^{\circ} \mathrm{C}, 130 \mathrm{MPa}, \mathrm{ds}=0.167 \mu \mathrm{m}$ \\
\hline$\longrightarrow$ Creep, $650^{\circ} \mathrm{C}, 100 \mathrm{MPa}, \mathrm{ds}=0.1 \mu \mathrm{m}$ & $\square \quad$ Creep-fatigue, $10 \mathrm{~min}$ hold, ds $=0.25 \mu \mathrm{m}$ \\
\hline - D-- Creep-fatigue, $650^{\circ} \mathrm{C}, 10 \mathrm{~min}$ hold, ds $=0.167 \mu \mathrm{m}$ & --- Creep-fatigue, $650^{\circ} \mathrm{C}, 10 \mathrm{~min}$ hold, $\mathrm{ds}=0.1 \mu \mathrm{m}$ \\
\hline$\diamond \quad$ Creep-fatigue, $650^{\circ} \mathrm{C}, 30 \mathrm{~min}$ hold, $\mathrm{ds}=0.25 \mu \mathrm{m}$ & $\triangle \quad$ Creep-fatigue, $650^{\circ} \mathrm{C}, 30 \mathrm{~min}$ hold, $\mathrm{ds}=0.167 \mu \mathrm{m}$ \\
\hline - Creep-fatigue, $650^{\circ} \mathrm{C}, 30 \mathrm{~min}$ hold, ds $=0.1 \mu \mathrm{m}$ & \\
\hline
\end{tabular}

\subsection{3}

Mod.9Cr steel

(Creep-fatigue:1\% strain range)
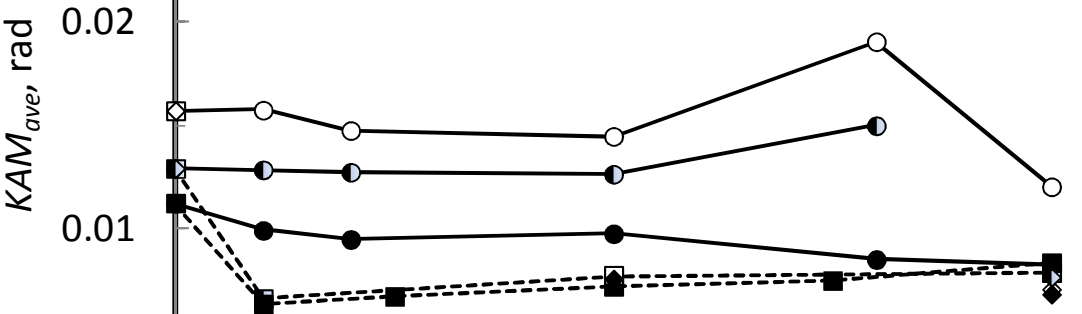

0

$\begin{array}{llllll}0 & 0.2 & 0.4 & 0.6 & 0.8 & 1 \\ & \text { Time fraction or cycle fraction } t / t_{r}, N / N_{f} & \end{array}$

Fig.9. Relationships between $K A M_{\text {ave }}$ and time or cycle fraction for creep and creep-fatigue tests of Mod.9Cr steel.

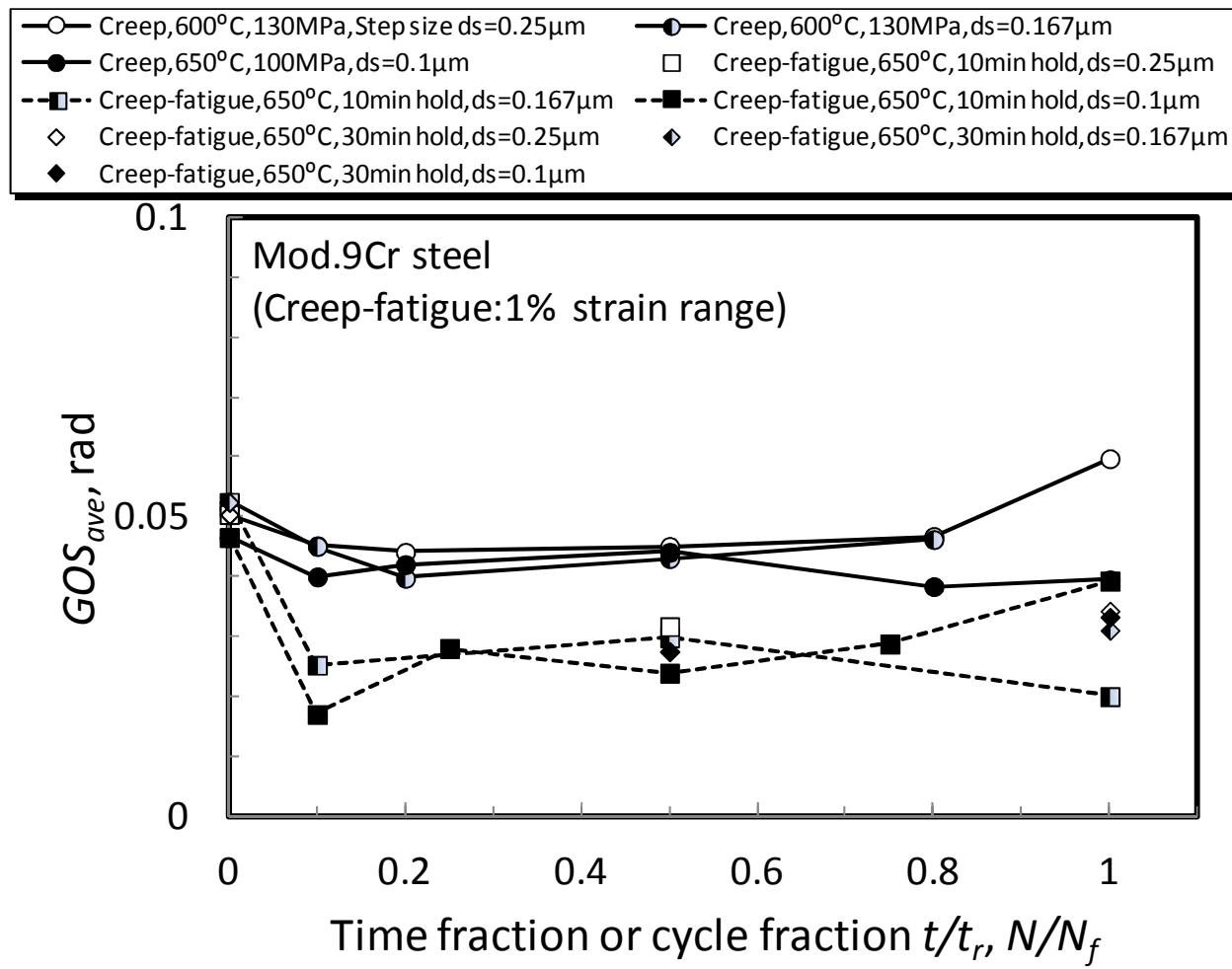

Fig.10. Relationships between $G O S_{\text {ave }}$ and time or cycle fraction for creep and creep-fatigue tests of Mod.9Cr steel. 


\section{Discussion}

As the misorientation metrics themselves are not the direct measures of plastic or creep permanent strains, a new parameter is required for representing accumulated permanent strains during the creep and creep-fatigue damage process. We call this parameter as "EBSD strain parameter" [7]. The theoretical basis for defining this parameter is as follows.

If we assume the misorientation angle $M$ is caused by the existence of total $n$ dislocations with Burgers vector $b$ within the unit pixel of characteristic step size $d_{s}$, the misorientation angle $M$ is approximated as;

$$
M=\frac{n b}{d_{s}}=\frac{n}{d_{s}^{2}} b d_{s} \approx \rho b d_{s}
$$

where, $\rho$ is the dislocation density approximated as $n / d_{s}^{2}$ for the thickness of unity.

The permanent strain induced by dislocation motion can be expressed by the following equation by the dislocation theory.

$$
\gamma_{p}=\rho_{m} b d_{B}
$$

where, $\rho_{m}$ :dislocation density moved during the permanent deformation, $d_{B}$ : dislocation mobile distance between boundaries defined as the border over the special misorientation value depending on the materials.

By substituting Eq.(1) into Eq.(2), we obtain the following relationship.

$$
\gamma_{p} \approx M \frac{d_{B}}{d_{s}}
$$

In Eq.(3), $M$ is attributed as KAM related values in this study. We use two quantities here as the KAM related values $K A M_{\text {net }}$ and $\delta K A M_{\text {ave }}$ as follows.

$$
\begin{aligned}
& K A M_{\text {net }}=K A M_{\text {ave }}-K A M_{0} \\
& \delta K A M_{\text {ave }}=\left|K A M_{\text {ave }}-K A M_{i}\right|
\end{aligned}
$$

$K A M_{n e t}$ in Eq.(4) means the net value of $K A M_{\text {ave }}$ subtracting the common minimum value $K A M_{0}$ irrespective of damage level. $K A M_{0}$ is introduced here as the assumption that there is a unique baseline value of $K A M$ irrespective of observation magnification and damage amount like a "background noise level" caused by the EBSD equipment itself.

$\delta K A M_{\text {ave }}$ in Eq.(5) means the absolute value of the change in $K A M_{\text {ave }}$ form initial value $K A M_{i}$ obtained from the unused materials. Here $K A M_{\mathrm{i}}$ was attributed here to the undamaged materials value of $K A M_{\text {ave }}$. $\delta K A M_{\text {ave }}$ can be obtained more easily than $K A M_{\text {net }}$ without determining $K A M_{0}$.

Figures 11 and 12 suggest almost linear relationship between $K A M_{\text {ave }}$ and step size $d_{s}$. The step size $2 \mu \mathrm{m}$ is excluded from the regression for SUS304HTB in Fig.11 because this size is thought to be too large for maintaining adequate resolution of intragranular misorientation distribution. Then the following linear equation between $K A M_{\text {ave }}$ and $d_{\mathrm{s}}$ can be obtained for various degree of damage by regression.

$$
K A M_{\text {ave }}=A_{K} d_{s}+K A M_{0}
$$

where, $A_{K}$ is regression constant but has different value according to damage.

The regression by Eq.(6) was actually conducted in the following manner.

1)The unique value for $K A M_{0}$ was set as the unused material's mean value over different $d_{s}$ for SUS304HTB while as the average of lower bound values in creep and creep-fatigue over different $d_{s}$ for Mod.9Cr steel. The values of $K A M_{0}$ were 0.00549 for SUS304HTB and 
0.00698 for Mod.9Cr steel in radian scale respectively.

2)The individual slope value of $A_{K}$ was determined by minimizing the sum square of the residuals from Eq.(6), i.e., $\Sigma\left|K A M_{a v e}-\left(A_{K} d_{s}+K A M_{0}\right)\right|^{2}$, the values were 0.0096 for SUS304HTB and 0.0043 for Mod.9Cr steel respectively in radian scale.

Note that from Eq.(4) and Eq.(6), $K A M_{n e t} / d_{s}$ is independent on $d_{s}$, i.e., observation magnification within the limited range, which is a convenient result for KAM measure.
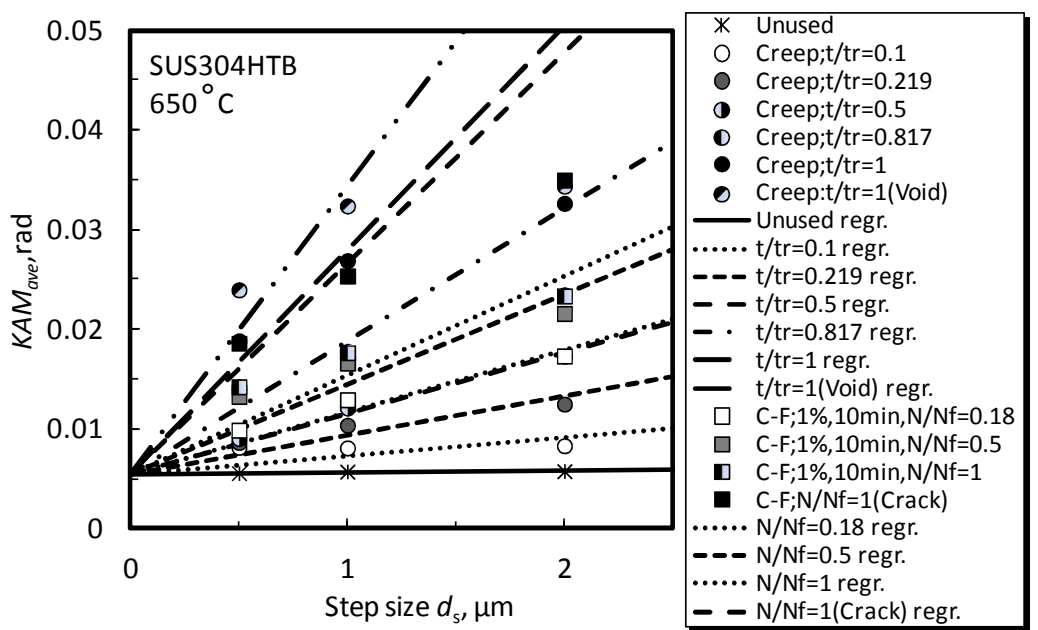

Fig.11. Regression analysis for determining the unique $K A M_{0}$ value of SUS304HTB.

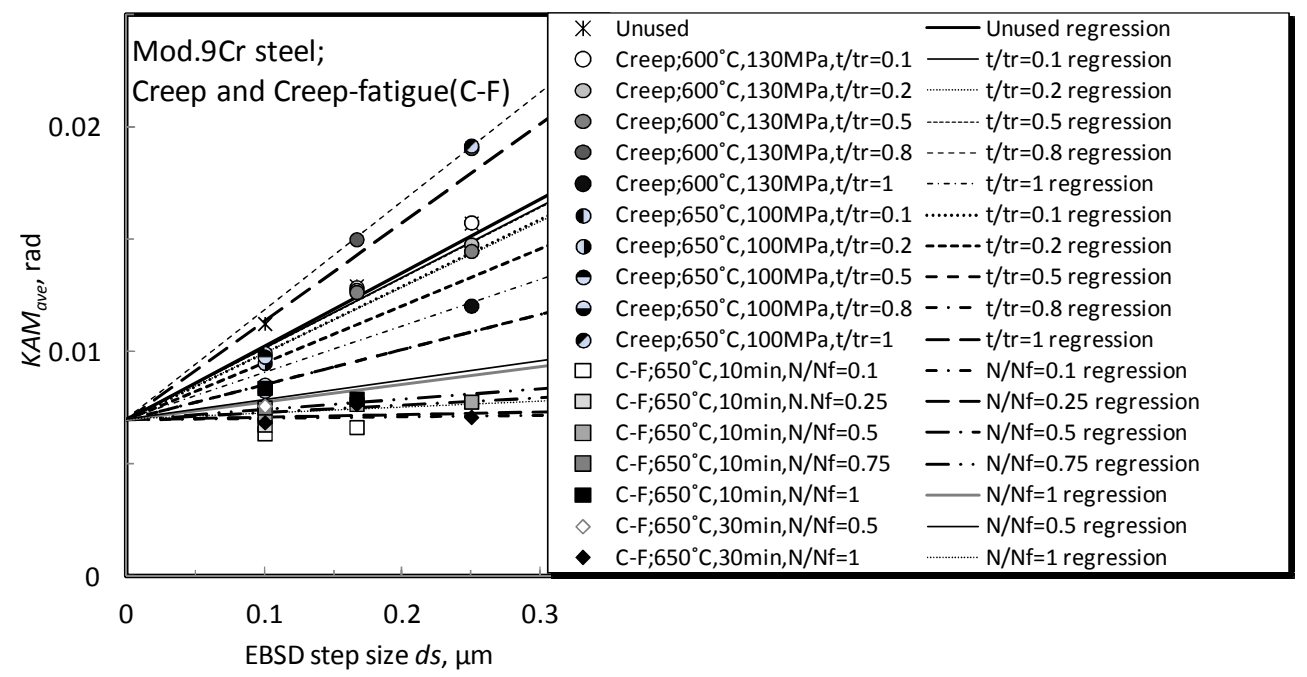

Fig.12. Regression analysis for determining the unique $K A M_{0}$ value of Mod.9Cr steel.

We define the dislocation mobile distance $d_{B}$ as the grain boundary spacing for SUS304HTB and the block boundary spacing for Mod.9Cr steel according to the microstructural features. Figure 13 shows the definition of boundary spacing $d_{B}$ from KAM maps for SUS304HTB and Mod.9Cr steel. The scanning lines are inclined $45^{\circ}$ to the loading axis to measure the dislocation mobile spacing along assumed maximum shear stress direction, which may cause the permanent strain, though this rule is not mandatory. The boundary is identified as the grain boundary or twin boundary with over 15 degrees for SUS304HTB, and as prior austenite grain boundary or block boundary with over 5 degree for Mod.9Cr steel. The boundary spacing $d_{B}$ is defined as the distance between two adjacent intersections of neighboring boundaries on the same scanning line.

Then $K A M_{n e t}$ strain parameter $M_{\varepsilon K A M n e t}$ and $\delta K A M_{\text {ave }}$ strain parameter $M_{\varepsilon \delta K A M a v e}$ can be 
defined as follows analogous to Eq.(3) using $K A M_{\text {net }}$ or $\delta K A M_{\text {ave }}$ as $M$.

$$
\begin{aligned}
& M_{\varepsilon \text { EAMnet }} \equiv K A M_{n e t} \frac{d_{B}}{d_{s}} \\
& M_{\varepsilon \delta \text { KAMave }} \equiv \delta K A M_{\text {ave }} \frac{d_{B}}{d_{s}}
\end{aligned}
$$

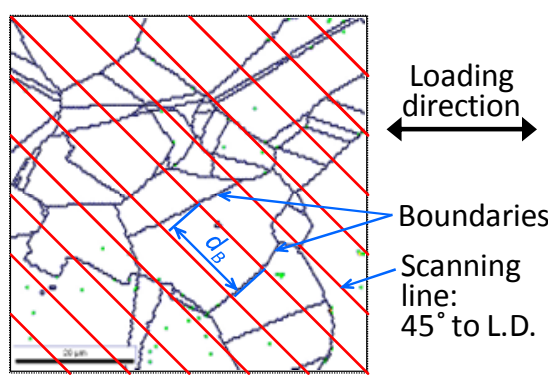

(a)SUS304HTB

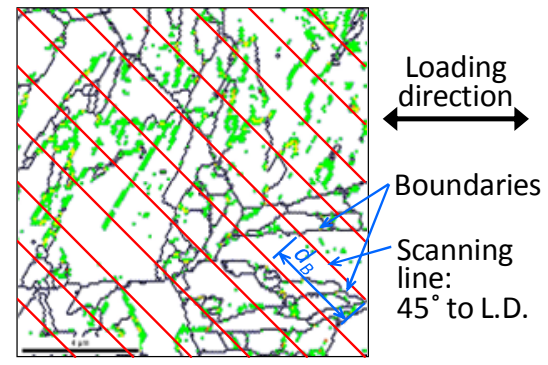

(b)Mod.9Cr steel

Fig.13. Definition of characteristic boundary spacing.

Figures 14 and 15 show the change of boundary spacing with time fraction and cycle fraction in creep and creep-fatigue tests for SUS304HTB and Mod.9Cr steel. The trends are almost opposite for those two materials, that is, SUS304HTB shows decreasing trend while Mod.9Cr steel shows rather increasing trend. The major cause of the decrease in $d_{B}$ for SUS304HTB may be attributed to the deformation of grains toward the loading axis and the increase in precipitation areas.

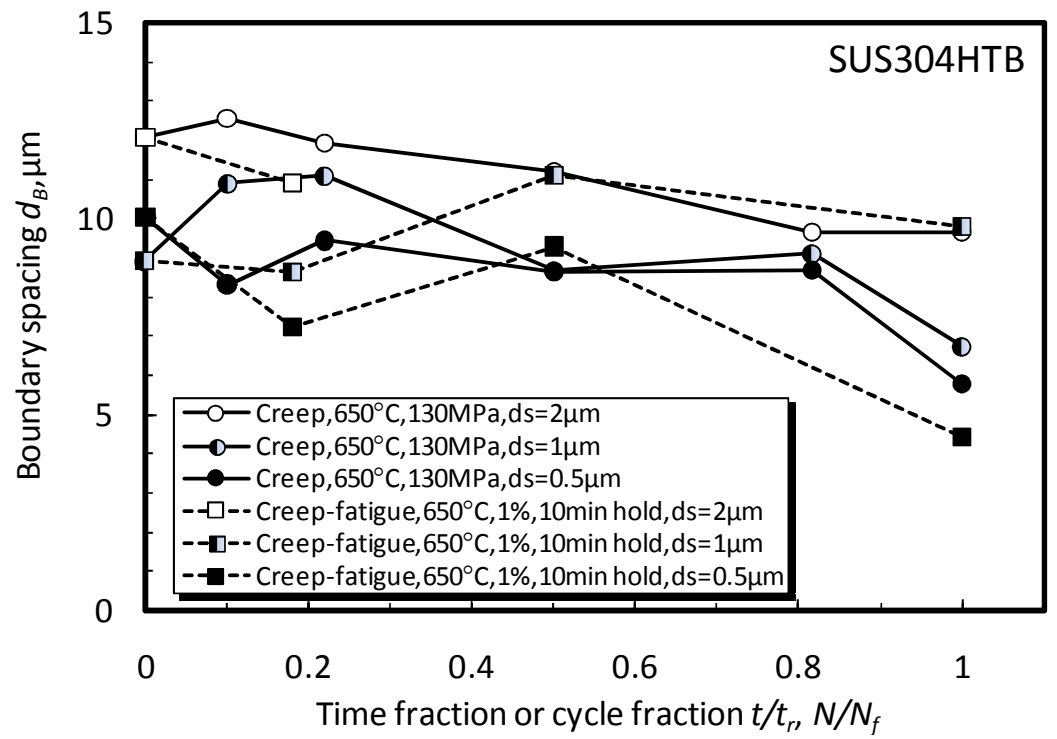

Fig.14. The change of boundary spacing against time fraction or cycle fraction for creep and creep-fatigue tests of SUS304HTB. 

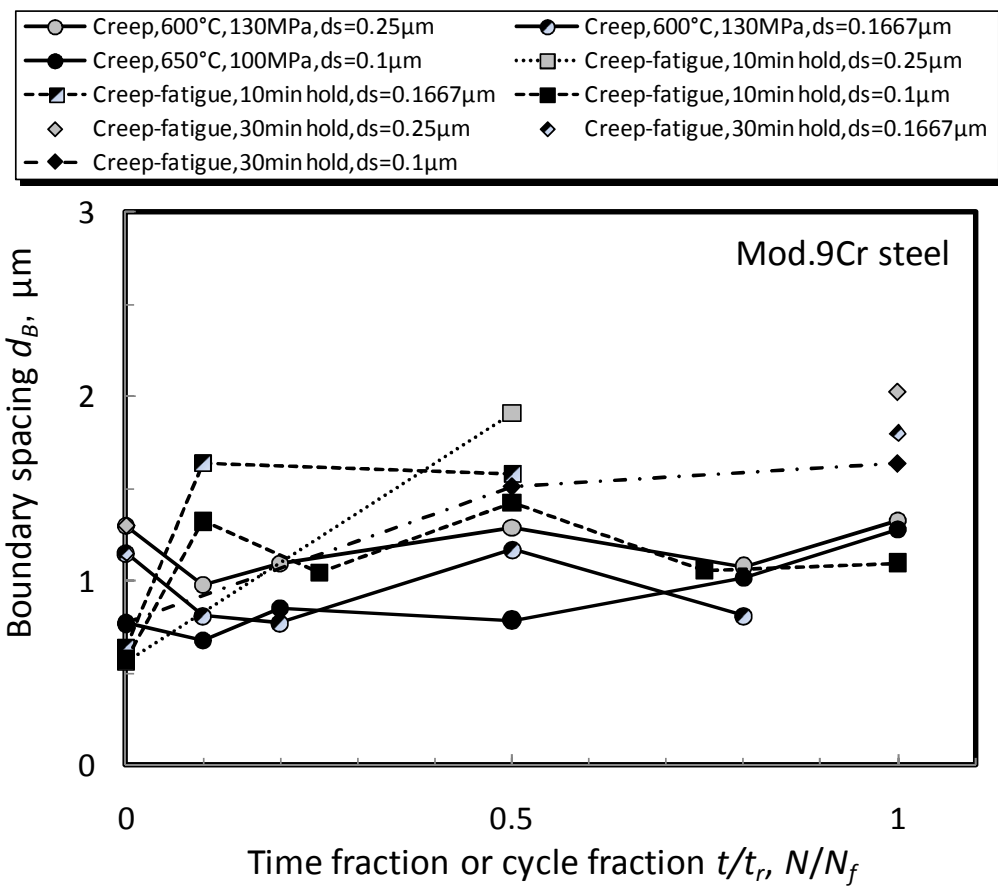

Fig.15. The change of boundary spacing against time fraction or cycle fraction for creep and creep-fatigue tests of Mod.9Cr steel.

Figures 16 and 17 show the relationship between the strain parameters with creep strain $\varepsilon_{c}$ or accumulated creep strain $N \Delta \varepsilon_{c}$ for creep-fatigue tests for SUS304HTB. The creep strain values corresponding to $t / t_{r}$ were listed in Tables 4 and 5. $N \Delta \varepsilon_{c}$ is the product of number of cycles $N$ (interrupted cycles or cycles to failure $N_{\mathrm{f}}$ ) and creep strain range $\Delta \varepsilon_{c}$ which is interpreted as the accumulated tensile (unbalanced) creep strain component. $M_{\varepsilon K A M n e t}$ and $M_{\varepsilon \delta K A M a v e}$ show almost similar increasing trend with the increase in creep strain components, especially indicating good correspondency between creep and creep-fatigue data approximately below the creep strain value of 0.2 . This result suggests that the strain parameters may represent the one-way( or unbalanced) accumulation of strain during the damage process except in the later stage of damage. As the saturating trends near failure can be interpreted as the localization of strain at the site of major cracks, the onset of saturation can be identified as the final failure stage of the damage process.

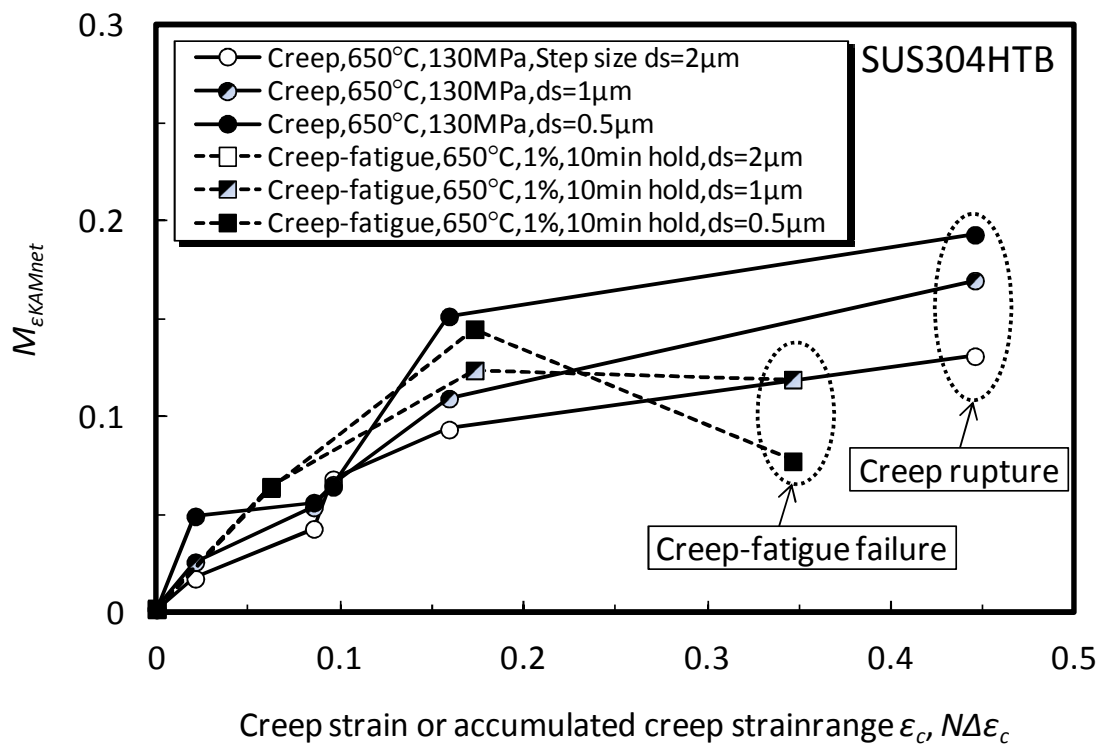

Fig.16. Relationships between $K A M_{\text {net }}$ strain parameter $M_{\varepsilon K A M n e t}$ and creep strain or accumulated creep strainrange for creep and creep-fatigue tests of SUS304HTB. 


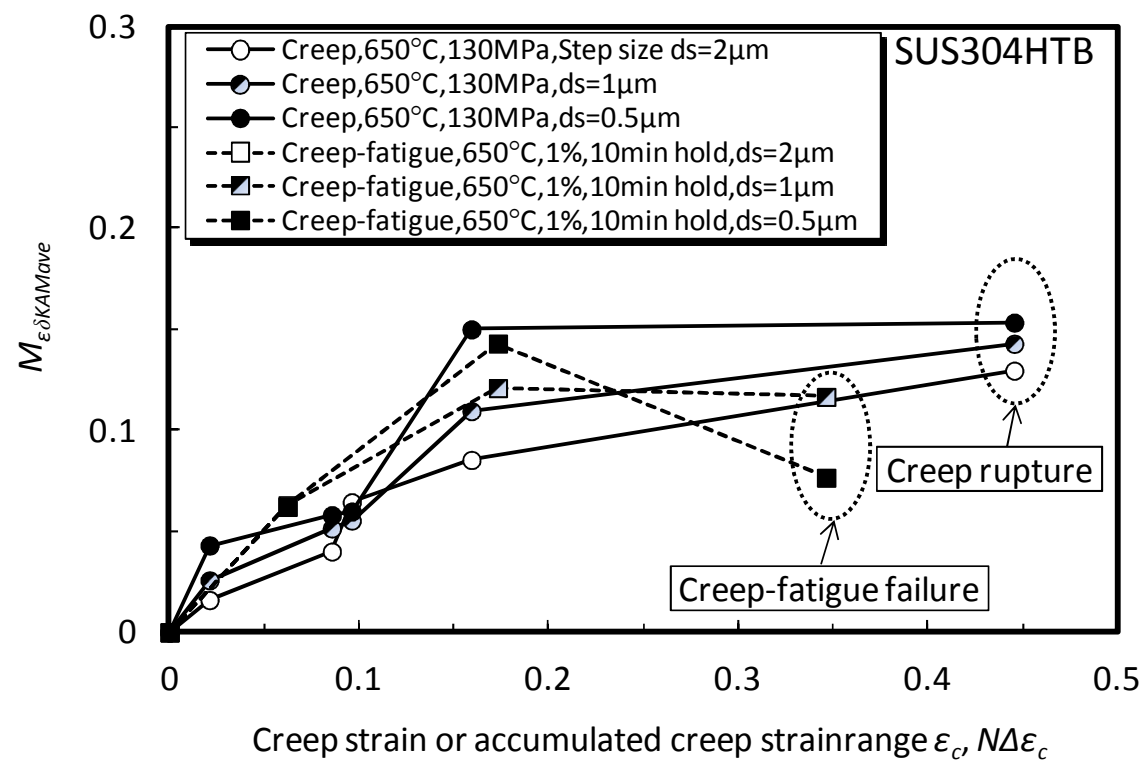

Fig.17. Relationships between $\delta K A M_{\text {ave }}$ strain parameter $M_{\varepsilon \delta K A M n e t}$ and creep strain or accumulated creep strainrange for creep and creep-fatigue tests of SUS304HTB.

Figures 18 and 19 show the relationship between the strain parameters and with creep strain $\varepsilon_{c}$ or accumulated creep strain $N \Delta \varepsilon_{c}$ for creep-fatigue tests for Mod.9Cr steel. $M_{\varepsilon K A M n e t}$ cannot represent the common increasing trend for creep and creep-fatigue against the stain accumulation while $M_{\varepsilon \delta K A M a v e}$ shows more common monotonic increase trend especially in the relatively early stage of creep and creep-fatigue. There also can be observed the end of increasing trends which suggest the strain localization probably due to major crack growth.

Therefore, $M_{\varepsilon \delta K A M a v e}$ is thought here as the better parameter for evaluating strain-based damage accumulation in creep and creep-fatigue process both for ferritic and austenitic heat resistance steels.

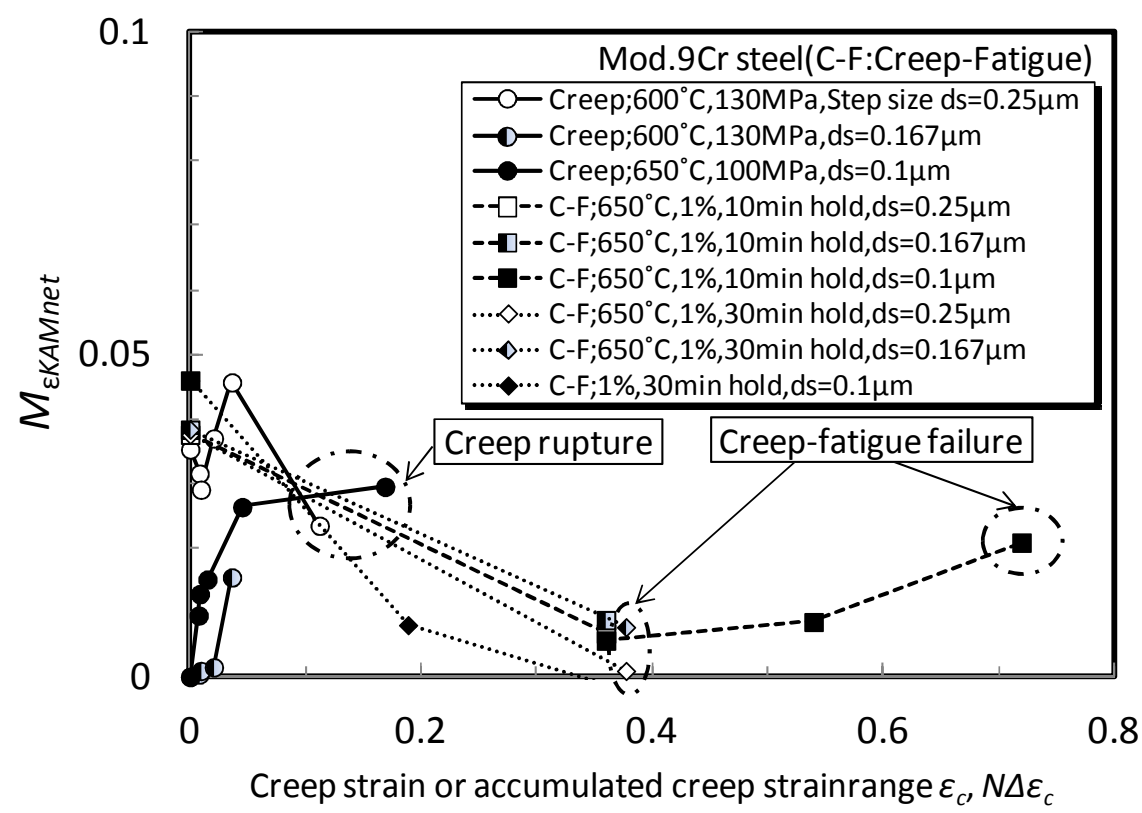

Fig.18. Relationships between $K A M_{n e t}$ strain parameter $M_{\varepsilon K A M n e t}$ and creep strain or accumulated creep strainrange for creep and creep-fatigue tests of Mod.9Cr steel. 


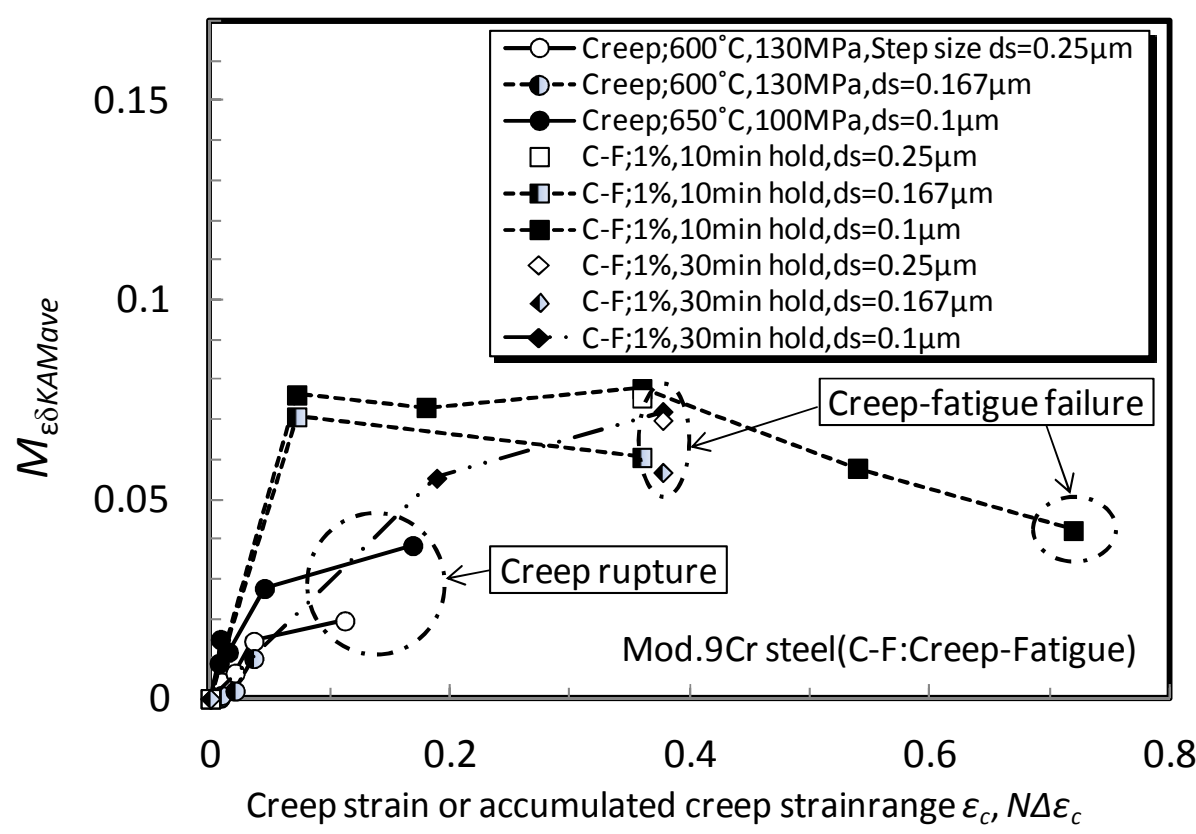

Fig.19. Relationships between $\delta K A M_{\text {ave }}$ strain parameter $M_{\varepsilon \delta K A M n e t}$ and creep strain or accumulated creep strainrange for creep and creep-fatigue tests of Mod.9Cr steel.

\section{Conclusion}

EBSD analyses for creep and creep-fatigue damage imposed materials were conducted on SUS304HTB and Mod.9Cr steel. Obtained results are as follows.

(1)EBSD misorientation parameters $K A M_{\text {ave }}$ and $G O S_{\text {ave }}$ showed opposite trend for SUS304HTB and Mod.9Cr steel. SUS304HTB showed increasing trend and Mod.9Cr steel showed decreasing trend with respect to time fraction and cycle fraction for creep and creep-fatigue damaged samples.

(2)Boundary spacing for SUS304HTB showed decreasing trend with damage accumulation mainly due to formation of twin boundaries, while that of Mod.9Cr steel showed rather increasing trend due to subgrain structure recovery.

(3)The strain parameter $M_{\varepsilon \delta K A M a v e}$ showed common monotonic increasing relationship with the accumulation of creep strain component in the relatively early stage of creep damage and creep-fatigue damage for either material. The end of the increasing trend was probably due to the onset of predominant strain localization due to major cracks which should be investigated in more detail.

\section{References}

[1] R. Ishii, Y. Tsuda, K. Fujiyama and K. Kimura, Proc. of 6th International Charles Parsons Turbine Conference, (2003)247-260.

[2] H. Okamura, R. Ohtani, K. Saito, K. Kimura, K. Fujiyama and R. Ishii, Fitness-for-Service Evaluations in Petroleum and Fossil Power Plants, PVP-Vol.380(1998)325-330.

[3] H. Kimura, Y. Wang, Y. Akiniwa and K. Tanaka, Trans. JSME Ser.A, 71 (2006) 1722-1728(in Japanese).

[4] M. Kamaya, J. INSS, 14(2007) 253-265(in Japanese). 
[5] R. Takaku, D. Saito and Y. Yoshioka, J. Soc. Mat. Sci., Japan, 58(2009) 229-234(in Japanese).

[6] K. Nomura, K. Kubushiro and S. Takahashi, Proc. of 59th JSMS Annual Meetings, (2010) 159-160(in Japanese).

[7] K. Fujiyama, K. Hijikuro, T. Tsuboi and H. Kimachi, Proc. of $7^{\text {th }}$ China-Japan Bilateral Symposium on High Temperature Strength of Materials, (2010)1-8. 